\title{
Marie-Étienne Vayssière, Ermite et provincial (1864-1940). Suivi de La dévotion à saint Dominique
}

Notes et souvenirs recueillis par Marie-Joseph Nicolas. Textes présentés par Serge-Thomas Bonino. Paris, Éditions du Cerf, coll. "Épiphanie », 2012, 99 p.

\section{Bernard Chédozeau}

\section{(2) OpenEdition}

Édition électronique

URL : http://journals.openedition.org/assr/24761

DOI : $10.4000 /$ assr. 24761

ISSN : $1777-5825$

Éditeur

Éditions de l'EHESS

\section{Édition imprimée}

Date de publication : 30 décembre 2012

Pagination : 299

ISSN : 0335-5985

\section{Référence électronique}

Bernard Chédozeau, « Marie-Étienne Vayssière, Ermite et provincial (1864-1940). Suivi de La dévotion à saint Dominique ", Archives de sciences sociales des religions [En ligne], 160 | octobre-décembre 2012, mis en ligne le 12 avril 2013, consulté le 21 septembre 2020. URL : http://journals.openedition.org/ assr/24761 ; DOI : https://doi.org/10.4000/assr.24761 


\section{Marie-Étienne Vayssière, Ermite et provincial (1864-1940). Suivi de La dévotion à saint Dominique}

Notes et souvenirs recueillis par Marie-Joseph Nicolas. Textes présentés par Serge-Thomas Bonino. Paris, Éditions du Cerf, coll. "Épiphanie », 2012, 99 p.

Bernard Chédozeau

\section{RÉFÉRENCE}

Marie-Étienne Vayssière, Ermite et provincial (1864-1940). Suivi de La dévotion à saint Dominique, Notes et souvenirs recueillis par Marie-Joseph Nicolas. Textes présentés par Serge-Thomas Bonino. Paris, Éditions du Cerf, coll. «Épiphanie », 2012, 99 p. 
1 À l'époque de la publication de la Bible de Port-Royal (1672-1708) qui accompagne la traduction du texte de l'explication littérale et de l'explication spirituelle de chaque verset de l'Écriture, et sous l'influence des nouvelles recherches critiques dont le Nouveau Testament de Richard Simon (1702) est un bon exemple, et très fréquemment depuis cette époque, l'intérêt pour le sens littéral est privilégié, et les «explications spirituelles» sont de plus en plus tenues en suspicion. Mais dans des écrits souvent souterrains, les spirituels ont toujours rappelé la valeur des sens spirituels et "mystiques", et se survit chez eux l'urgence de l'expérience et de « la beauté spirituelle».

Le Père Serge-Thomas Bonino, OP, consultant de la Congrégation pour la Doctrine de la Foi, est de ceux-là. Dans sa
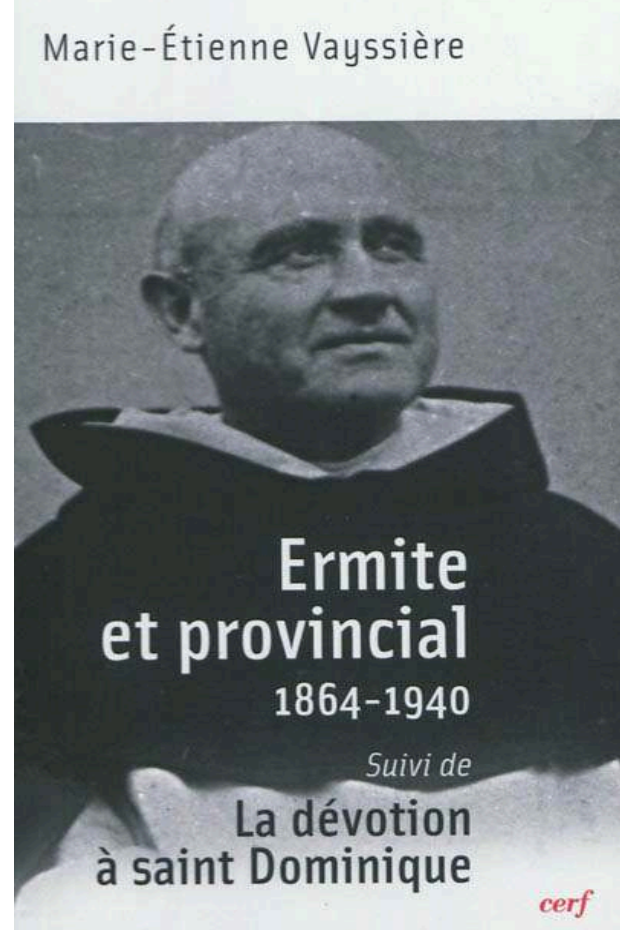
présentation de Ermite et provincial 1864-1940 (notice rédigée par le frère Marie-Joseph Nicolas après la mort du Père Vayssière, déjà parue dans La Vie spirituelle, $\mathrm{n}^{\circ} 252$, d'avril 1941, p. 268-286, et imprimée sous forme de tiré à part, la même année, aux Éditions de l'Abeille, 9 rue Mulet, à Lyon), certes il reconnaît l'utilité de «l'objectivité austère des historiens », car elle permet de " désherber les vies édifiantes et éliminer les pieusardises qui les parasitent » (p. 13) - au-delà des niaiseries pieuses, on peut penser à la condamnation de « la mystiquerie » par R. Simon. " Mais pour entrer vraiment dans l'âme d'un saint, rien ne vaut [...] quelqu'un qui sait par expérience ce dont il s'agit ». C'est ainsi que le P. Marie-Joseph Nicolas - l'auteur de la notice - a su introduire les lecteurs spirituels dans la «vie intérieure exceptionnelle » du P. Vayssière, en l'illustrant par une méditation sur les grâces dont a été gratifié l'ermite : "Grâce de la souffrance [en raison de son impuissance physique, et le "laisser faire”, p. 22], grâce de la solitude [à la Sainte-Baume, où s'affirma l'ermite contemplatif], grâce de l'intimité mariale ["la source de la foi, c'est Marie" pour "revivre la vie même de Jésus à Nazareth", et avec le rosaire], grâce de la paternité [pendant les années du provincialat]", tous aspects expliqués et développés par l'auteur pour faciliter l'adhésion non par la connaissance mais par le cœur ["il voulait qu'on adhérât par le cœur"], en un très riche portrait d'ermite et de solitaire, puis de provincial.

3 Le second texte, La Dévotion à saint Dominique, est une lettre du Père Vayssière adressée le 21 avril 1935 aux dominicains de la province de Toulouse (à la suite des festivités célébrant le septième centenaire de la canonisation, en 1234, de saint Dominique. Elle est parue dans La Vie spirituelle, $\mathrm{n}^{\circ} 663$, de janvier-février 1985, p. 107-123.) C'est encore le $\mathrm{P}$. Bonino qui présente ce texte où, après le contemplatif, c'est le maître spirituel qui se révèle dans le $\mathrm{P}$. Vayssière. Tombé gravement malade à vingt-quatre ans, après un temps d'errances, il est envoyé à la grotte de la Sainte-Baume dont il est gardien de 
1900 à 1932 (par la suite il sera de 1932 à 1940 prieur provincial de la province de Toulouse). « Il ne peut ni prêcher, ni lire, ni même prier ». Mais c'est là qu'il découvre, vit et définit la dévotion à saint Dominique, dont il rappelle à ses frères qu'elle fait leur place «dans la splendeur des saints »: «Voilà notre éternité : en Dominique et avec Dominique toujours » (p. 72).

4 Cette dévotion à saint Dominique repose sur le culte des saints ainsi entendu : "La gloire de Dieu est d'associer généreusement les créatures à son action de salut » pour qu'ils deviennent «instruments de salut pour leurs frères ». Grâce au P. Vayssière, guide spirituel «qui montre les voies de Dieu», les dominicains sont invités à jouir de sa "grâce d'union filiale à saint Dominique » (p. 57-59) pour "vivre ainsi le charisme dominicain »: "Regarde et vis en conformité avec le modèle dressé à tes yeux sur la montagne" (il est permis de penser à l'admirable Retable de Tetschen de Caspar David Friedrich), selon la " grâce de paternité » qui est « la grâce des patriarches ". C'est ainsi qu'à l'instar de tous les spirituels l'âme dominicaine "revit le Christ », certes ; mais comme le veut le contemplatif que fut le $\mathrm{P}$. Vayssière c'est « dans la grâce particulière de saint Dominique ».

Que ce soit à la Sainte-Baume ou à Toulouse, le P. Vayssière a su accepter de lourdes charges en sachant en faire la voie vers l'aide apportée aux autres. Ainsi prend tout son sens le titre un peu provocateur qui réunit érémitisme et direction d'une province.

Un bel ouvrage d'une solide et riche spiritualité. 